\title{
Warmer spring temperatures in temperate deciduous forests advance the timing of tree growth but have little effect on annual woody productivity
}

\section{Kristina Anderson-Teixeira ( $\square$ TeixeiraK@si.edu )}

Smithsonian Conservation Biology Institute https://orcid.org/0000-0001-8461-9713

\section{Cameron Dow}

Smithsonian Conservation Biology Institute

\section{Albert Kim}

Smith College https://orcid.org/0000-0001-7824-306X

\section{Loïc D\&\#039;Orangeville}

University of New Brunswick https://orcid.org/0000-0001-7841-7082

\section{Erika Gonzalez-Akre}

Smithsonian Conservation Biology Institute

\section{Ryan Helcoski}

Smithsonian Conservation Biology Institute https://orcid.org/0000-0003-3579-0121

\section{Valentine Herrmann}

Smithsonian Conservation Biology Institute https://orcid.org/0000-0002-4519-481X

\section{Grant Harley}

University of Idaho https://orcid.org/0000-0003-1557-8465

Justin Maxwell

Indiana University Bloomington https://orcid.org/0000-0001-9195-3146

lan McGregor

Smithsonian Conservation Biology Institute

\section{William McShea}

Smithsonian Conservation Biology Institute

\section{Sean McMahon}

Smithsonian Tropical Research Institute https://orcid.org/0000-0001-8302-6908

\section{Neil Pederson}

Harvard University https://orcid.org/0000-0003-3830-263X

\section{Alan Tepley}

Smithsonian Conservation Biology Institute https://orcid.org/0000-0002-5701-9613 


\section{Biological Sciences - Article}

\section{Keywords:}

Posted Date: December 15th, 2021

DOI: https://doi.org/10.21203/rs.3.rs-1093360/v1

License: (c) (i) This work is licensed under a Creative Commons Attribution 4.0 International License. Read Full License

Version of Record: A version of this preprint was published at Nature on August 10th, 2022. See the published version at https://doi.org/10.1038/s41586-022-05092-3. 
1 Title: Warmer spring temperatures in temperate deciduous forests advance the timing of tree

2 growth but have little effect on annual woody productivity

3 Authors:

4 Cameron Dow ${ }^{1,2}$ ( Orcid ID : 0000-0002-8365-598X)

$5 \quad$ Albert Y. Kim ${ }^{1,3}$ ( Orcid ID : 0000-0001-7824-306X)

6 Loïc D'Orangeville ${ }^{4,5}$ ( Orcid ID : 0000-0001-7841-7082)

7 Erika B. Gonzalez-Akreㄹ ( Orcid ID : 0000-0001-8305-6672)

$8 \quad$ Ryan Helcoski ${ }^{1}$

9 Valentine Herrmann¹ ( Orcid ID : 0000-0002-4519-481X)

10 Grant L. Harley ${ }^{6}$ ( Orcid ID : 0000-0003-1557-8465)

11 Justin T. Maxwell7 (Orcid ID: 0000-0001-9195-3146)

12 Ian R. McGregor ${ }^{1,8}$ (Orcid ID: 0000-0002-5763-021X)

13 William J. McShea ${ }^{1}$

14 Sean McMahon ${ }^{9,11}$ (Orcid ID : 0000-0001-8302-6908)

15 Neil Pederson ${ }^{4}$ (Orcid ID : 0000-0003-3830-263X)

16 Alan J. Tepley ${ }^{1,10}$ ( Orcid ID : 0000-0002-5701-9613)

17 Kristina J. Anderson-Teixeira ${ }^{1,11 *}$ ( Orcid ID : 0000-0001-8461-9713)

18 Author Affiliations:

19 1. Conservation Ecology Center; Smithsonian Conservation Biology Institute; Front Royal, VA 20 22630, USA

21 2. Department of Forestry and Natural Resources, Purdue University, West Lafayette, Indiana, $22 \quad$ USA

23 3. Statistical \& Data Sciences; Smith College; Northampton, MA 01063, USA

24 4. Harvard Forest, Petersham, MA 01366, USA

25 5. Faculty of Forestry and Environmental Management, University of New Brunswick, 26 Fredericton, NB, E3B 5A3, Canada.

27 6. Department of Earth and Spatial Sciences, University of Idaho, ID 83844, USA

28 7. Department of Geography, Indiana University, Bloomington, IN 47405, USA 
29 8. Center for Geospatial Analytics; North Carolina State University; Raleigh, NC 27607, USA

30 9. Smithsonian Environmental Research Center, Edgewater, MD, USA

31 10. Canadian Forest Service, Northern Forestry Centre, Edmonton, Alberta, Canada

32 11. Forest Global Earth Observatory; Smithsonian Tropical Research Institute; Panama, 33 Republic of Panama

34 *corresponding author: teixeirak@si.edu; +1 5406356546

35 
As the climate changes, warmer spring temperatures are causing earlier leaf-out ${ }^{1-6}$ and commencement of net carbon dioxide $\left(\mathrm{CO}_{2}\right)$ sequestration ${ }^{2,4}$ in temperate deciduous forests, resulting in a tendency towards increased growing season length ${ }^{1,4,5,7-9}$ and annual $\mathrm{CO}_{2}$ uptake $^{2,4,10-14}$. However, less is known about how spring temperatures affect tree stem growth, which sequesters carbon (C) in wood that has a long residence time in the ecosystem ${ }^{15,16}$. Using dendrometer band measurements from 463 trees across two forests, we show that warmer spring temperatures shifted the woody growth of deciduous trees earlier but had no consistent effect on peak growing season length, maximum daily growth rates, or annual growth. The latter finding was confirmed on the centennial scale by 207 tree-ring chronologies from 108 forests across eastern North America, where annual growth was far more sensitive to temperatures during the peak growing season than in the spring. These findings imply that extra $\mathrm{CO}_{2}$ uptake in years with warmer springs ${ }^{10-12}$ is not allocated to long-lived woody biomass, where it could have a substantial and lasting impact on the forest C balance. Rather, contradicting current projections from global C cycle models ${ }^{2,3,17,18}$, our empirical results imply that warming spring temperatures are unlikely to increase the woody productivity or strengthen the $\mathrm{CO}_{2}$ sink of temperate deciduous forests.

In recent decades, Earth's forests have sequestered $\sim 20 \%$ of anthropogenic $\mathrm{CO}_{2}$ emissions, thereby slowing the pace of atmospheric $\mathrm{CO}_{2}$ accumulation and climate change ${ }^{19,20}$. A large

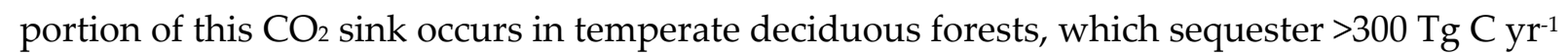
$(>30 \% \text { of the total forest } \mathrm{C} \text { sink })^{21}$. The future behavior of this $\mathrm{CO}_{2}$ sink will play an important yet uncertain role in influencing atmospheric $\mathrm{CO}_{2}$ and climate change $\mathrm{e}^{20,22}$. 
57 In temperate deciduous forests, spring warming generally lengthens the period over which

58 trees have photosynthetically active leaves ${ }^{1,7-9}$ and that over which the ecosystem is a net $\mathrm{CO}_{2}$

$59 \operatorname{sink}^{2}$. Current models assume that longer growing seasons lead to increasing annual net $\mathrm{CO}_{2}$

60 uptake (i.e., net ecosystem exchange, $N E E)^{2,3,17}$. However, recent experimental and observational

61 findings show that annual productivity can be limited by sink factors ${ }^{17,23,24}$, and that positive

62 effects of warm springs are compensated by negative effects of accumulation of seasonal water

63 deficits ${ }^{3}$. These studies suggest that warmer spring temperatures may not have the expected

64 positive effect on forest $\mathrm{CO}_{2}$ sequestration.

65 While responses of leaf phenology and seasonal NEE to warming spring temperatures have

66 been documented ${ }^{1-4,7-9}$, little is known about how the longest-lived component of fixed $\mathrm{C}$ in

67 trees, the woody growth, is responding to warming spring temperatures. In fact, we are aware

68 of only one study that has documented stem-growth phenology of temperate deciduous forests

69 over multiple years ${ }^{25}$. The climate sensitivity of woody growth phenology in temperate

70 deciduous trees and its link to annual growth has never been studied in-situ (but see Ref. ${ }^{24}$ for a

71 controlled sapling experiment).

72 Tree-ring records, which can be used to examine relationships of annual growth to temperature

73 but not to understand growth phenology, reveal that growth of temperate deciduous trees

74 tends to be most sensitive to temperature or potential evapotranspiration between late spring

75 and early summer 26,27 , with some hints that warmer springs may have a modest positive effect

76 on growth ${ }^{27}$. Thus, tree-ring evidence does not necessarily align with the finding that warming

77 spring temperatures increase annual forest $\mathrm{CO}_{2}$ uptake ${ }^{2}$. Characterizing phenological responses 
78 of stem growth to warming spring temperatures is critical to bridging this conceptual

79 disconnect and understanding how forest biomass growth is likely to change as the climate

80 warms.

81 Here, we evaluate how early spring temperatures affect stem growth phenology, growth rates,

82 and annual growth of temperate deciduous trees across eastern North America. To test whether

83 warmer springs extend the period of stem growth, we used dendrometer band measurements

84 on 463 trees across two mid-latitude forests. To test whether spring temperatures consistently

85 increased annual growth, we analyzed 207 tree-ring chronologies from 108 forests.

86 Dendrometer band analysis

87 Using dendrometer band measurements taken throughout multiple growing seasons at the

88 Smithsonian Conservation Biology Institute (SCBI; Virginia, USA; $\mathrm{n}=123$ trees from 2011-2020)

89 and Harvard Forest (Massachusetts, USA; $\mathrm{n}=340$ trees from 1998-2003), we fit a logistic growth

90 model ${ }^{28}$ to determine the days of year (DOY) when 25, 50, and 75\% annual growth were

91 achieved $\left(D O Y_{25}, D O Y_{50}, D O Y_{75}\right)$, peak growing season length $\left(L_{p g s}=D O Y_{75}-D O Y_{25}\right)$, the

92 maximum daily growth rates $\left(g_{\max }\right)$ and the DOY on which it occurred $\left(D O Y_{g_{\max }}\right)$, and total

93 annual increment in diameter at breast height $(\triangle D B H$; Fig. 1$)$. This analysis was performed

94 separately for ring- and diffuse-porous species, which differ in growth phenology ${ }^{25}$. These stem-

95 growth milestones were compared to canopy foliage phenology (measured at ecosystem level

96 via remote sensing). 
(a)

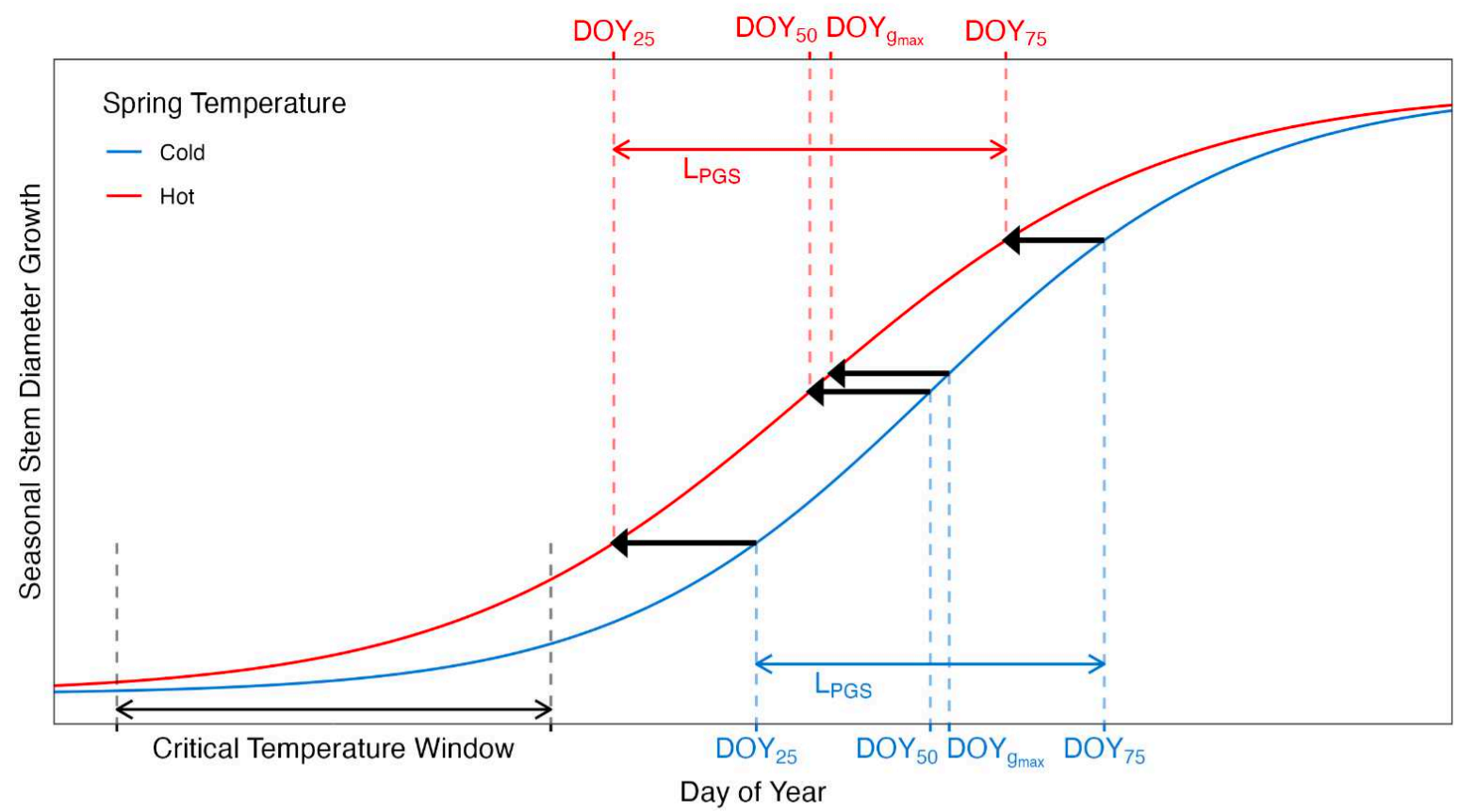

(b)

\begin{tabular}{|c|c|c|c|c|c|}
\hline \multirow[b]{3}{*}{ Variable } & \multirow[b]{3}{*}{ Definition } & \multicolumn{4}{|c|}{ Response to warmer spring $\mathbf{T}$} \\
\hline & & \multicolumn{2}{|c|}{ SCBI } & \multicolumn{2}{|c|}{ Harvard Forest } \\
\hline & & $\mathrm{RP}$ & DP & $\mathrm{RP}$ & DP \\
\hline \multicolumn{6}{|c|}{ Timing of growth } \\
\hline$D O Y_{25}$ & day of year at which $25 \%$ of growth is achieved & $\downarrow$ & $\downarrow$ & $\downarrow$ & $\downarrow$ \\
\hline$D O Y_{50}$ & day of year at which $50 \%$ of growth is achieved & $\downarrow$ & $\downarrow$ & $\downarrow$ & $\downarrow$ \\
\hline$D O Y_{75}$ & day of year at which $75 \%$ of growth is achieved & $\downarrow$ & $\downarrow$ & $\downarrow$ & $\downarrow$ \\
\hline$D O Y_{g_{\max }}$ & day of year of max growth rate & $\downarrow$ & $\downarrow$ & $\downarrow$ & $\downarrow$ \\
\hline$L_{P G S}$ & peak growing season length $\left(D O Y_{75}-D O Y_{25}\right)$ & $\uparrow$ & - & $\downarrow$ & $\uparrow$ \\
\hline \multicolumn{6}{|c|}{ Daily growth rate } \\
\hline$g_{\max }$ & maximum daily growth rate & - & - & $\uparrow$ & $\downarrow$ \\
\hline \multicolumn{6}{|c|}{ Annual growth } \\
\hline$\triangle D B H$ & annual growth & - & - & - & - \\
\hline$R W I$ & ring width index from tree-ring chronologies & mixed & mixed & - & mixed \\
\hline
\end{tabular}

Figure 1 I Summary of temperate deciduous tree growth responses to warmer spring temperatures. (a) Schematic illustrating parameters of interest and summarizing how each responds to warmer maximum temperatures during a 'critical temperature window', defined as the period with the strongest control over $\mathrm{DOY}_{25}$; (b) Variable definitions and summary of responses to warmer spring temperatures at two temperate forests - Smithsonian Conservation Biology Institute (SCBI) and Harvard Forest - and for two groups of broadleaf deciduous species ( $\mathrm{RP}=$ ring porous; $\mathrm{DP}=$ diffuse porous), where up and down arrows indicate significant increases and decreases, respectively, '-' indicates no significant correlation, and 
106 Growth milestones for both canopy foliage phenology and stem growth occurred 6-10 days

107 earlier, on average, at SCBI than at Harvard Forest (Fig. 2, Extended Data Table 2). Consistent

108 with the results of $\operatorname{Ref}^{25}$, ring-porous species began growing earlier, reaching the $D O Y_{25}$

109 benchmark earlier (by 31 days at SCBI and 32 at Harvard Forest), and their growth was spread

110 over a longer growing season (average $L_{P G S} 21$ and 19 days longer at SCBI and Harvard Forest,

111 respectively; Fig. 2, Extended Data Figure 2, Extended Data Table 2). Peak growing season

112 length was similar across sites, with $L_{P G S}$ being, on average, only two days longer at SCBI for

113 ring-porous species and less than one day longer for diffuse-porous species (Extended Data

114 Table 2). 

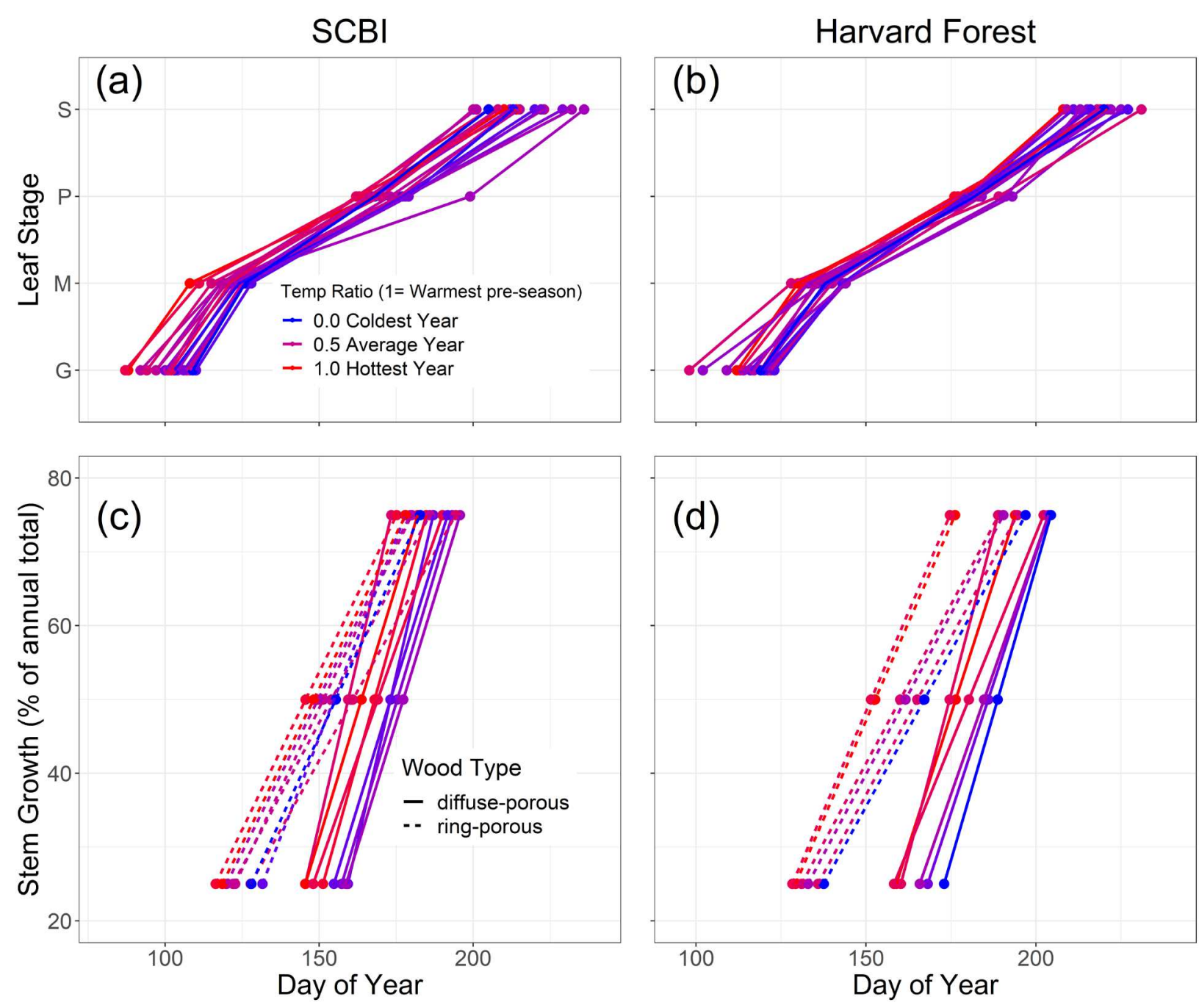

Figure 2 | Foliage $(a, b)$ and stem growth $(c, d)$ phenology at the Smithsonian Conservation Biology Institute $(\mathbf{a}, \mathbf{c})$ and Harvard Forest $(\mathbf{b}, \mathbf{d})$. Panels $(\mathrm{a}-\mathrm{b})$ show ecosystem-level canopy foliage phenology from 2001-2018, obtained from the MODIS Global Vegetation Phenology product (MCD12Q2.006), where $\mathrm{G}=$ Greenup, $\mathrm{M}=$ Mid-greenup, $\mathrm{P}=$ peak, and $\mathrm{S}=$ Senescence (i.e., beginning of green-down). Panels (c-d) show the dates at which stem growth milestones were achieved, on average, for sampled populations of ring-porous and diffuse-porous trees at SCBI (2011-2020) and Harvard Forest (1998-2003). Mean temperature was calculated for each wood-type/site combination over the respective critical $\mathrm{T}_{\max }$ window, then turned into a ratio and assigned a color on a gradient where the coldest year in the sample is blue and the warmest is red. growth phenology generally shifted backwards as spring temperatures increased (Fig. 2, 
129 throughout the spring, but the strongest effects on stem-growth phenology were found using

$130 T_{\max }$ during a critical temperatrue window (CTW). CTW was identified by measuring the 131 correlation between all combinations of weekly $T_{\max }$ and $D O Y_{25}$ from January 1 to mean $D O Y_{25}$

132 for each xylem porosity-site combination (Extended Data Figure 3). The CTW was defined as

133 the week(s) which had the strongest correlation with $D O Y_{25}$.

134 For ring- and diffuse- porous species at both sites, warmer $T_{\max }$ in the CTW resulted in earlier 135 achievement of phenological milestones. Consistent with findings from previous studies ${ }^{30}$, leaf 136 phenological milestones advanced at both sites (Fig. 2a-b, Extended Data Table 2), with greenup 137 (DOY when EVI2 first crossed 15\% of the segment EVI2 amplitude) advancing 4.5 days $/{ }^{\circ} \mathrm{C}$ at 138 SCBI ( $\mathrm{p}=0.001)$ and 2.4 days $/{ }^{\circ} \mathrm{C}$ at Harvard Forest $(\mathrm{p}=0.1)$. Similarly, at both sites, the stem 139 growth milestones $D O Y_{25}, D O Y_{50}, D O Y_{75}$, and $D O Y_{g_{\max }}$ all decreased with mean $T_{\text {max }}$ during the 140 critical temperature window (Figs. 1, 2c-d; Extended Data Figures 4-5). Specifically, $D O Y_{25}$, $141 \mathrm{DOY}_{50}$, and $\mathrm{DOY} 75$ advanced $1.1-1.9$ days $/{ }^{\circ} \mathrm{C}$ for ring-porous species and 3.5-3.6 days $/{ }^{\circ} \mathrm{C}$ for 142 diffuse-porous species at SCBI, and 2.8-7.2 days/ ${ }^{\circ} \mathrm{C}$ for ring-porous species and $6.6-7.9$ days/ ${ }^{\circ} \mathrm{C}$ 143 for diffuse-porous species at Harvard Forest (Extended Data Table 2).

144 Whereas the length of time between canopy greenup and senescence (i.e., the day when 145 greenness dropped below $90 \%$ of its peak) increased in years with warmer temperatures during 146 the critical temperature window compared to those with cooler temperatures (Fig. 2a-b), there 147 was no consistent lengthening of $L_{P G S}$ (Fig. 1, Extended Data Figures 4-5).

148 In contrast to the pronounced effects of $T_{\max }$ on the timing of growth, its effects on $g_{\max }$ and $149 \triangle D B H$ were weak and inconsistent (Figs. 1, Extended Data Figures 4-5). Specifically, $g_{\max }$, 
150 which occurred very close to $D O Y_{50}$ (on $D O Y_{\text {g.max }}$; Extended Data Table 2), displayed either no

151 relationship to mean $T_{\max }$ during the critical temperature window (SCBI), or extremely small

152 changes in opposite directions for ring- and diffuse- porous species (Harvard Forest). $\triangle D B H$

153 displayed no relationship with mean $T_{\max }$ during the critical temperature window (Extended

154 Data Figure 4).

Tree-ring analysis

156 To understand how annual growth increments have responded to spring temperatures at the

157 centennial scale, we analyzed tree-ring chronologies of 12 species at $\mathrm{SCBI}^{27}$ and 4 species at

158 Harvard Forest (Extended Data Table 1), along with an additional 191 chronologies from 106

159 sites (Fig. 3; Extended Data Figure 1; Extended Data Table 3) ${ }^{26}$. In total, our analysis included

160207 chronologies representing 24 broadleaf species at 108 sites distributed from Alabama $($ Lat $=$

$16134.35)$ to Michigan $($ Lat $=45.56)$ and spanning a $15{ }^{\circ} \mathrm{C}$ range in April $T_{\text {max }}$. Across all

162 chronologies, the standardized ring-width index (RWI) was significantly (at $\mathrm{p} \leq 0.05)$ positively

163 correlated with April $T_{\max }$ for only 2\% of chronologies: 1 of 142 ring-porous and 4 of 66 diffuse-

164 porous species-site combinations (Extended Data Table 3). In contrast, RWI was frequently

165 negatively correlated with $T_{\max }$ during peak growing season months (May-August), with

166 significant correlations for 52\% (May: 45/141, Jun: 107/141, Jul: 91/141, Aug: 53/141) and 46\%

167 (May: 10/66, Jun: 52/66, Jul: 36/66, Aug: 23/66) of species-site-month combinations for ring-

168 porous and diffuse-porous species, respectively. $T_{\min }$ generally exibited weaker relationships to

169 annual growth than $T_{\max }$, with few significant correlations between spring $T_{\min }$ and RWI

170 (Extended Data Figure 6). 
171 To test whether the negative effect of summer temperatures might offset an enhancement of

172 growth by warmer spring temperatures, we tested for the joint effects of April and June-July

$173 T_{\max }$ on RWI. Results were qualitatively similar to the univariate correlations (Fig. 3), with

174 significant (at $\mathrm{p}=0.05$ ) positive correlations to April $T_{\max }$ for only $4 \%$ of chronologies and

175 significant negative correlations with June-July $T_{\max }$ for $77 \%$ of chronologies, supporting that

176 summer temperatures were the more important driver of annual stem growth (Extended Data

177 Table 3). 

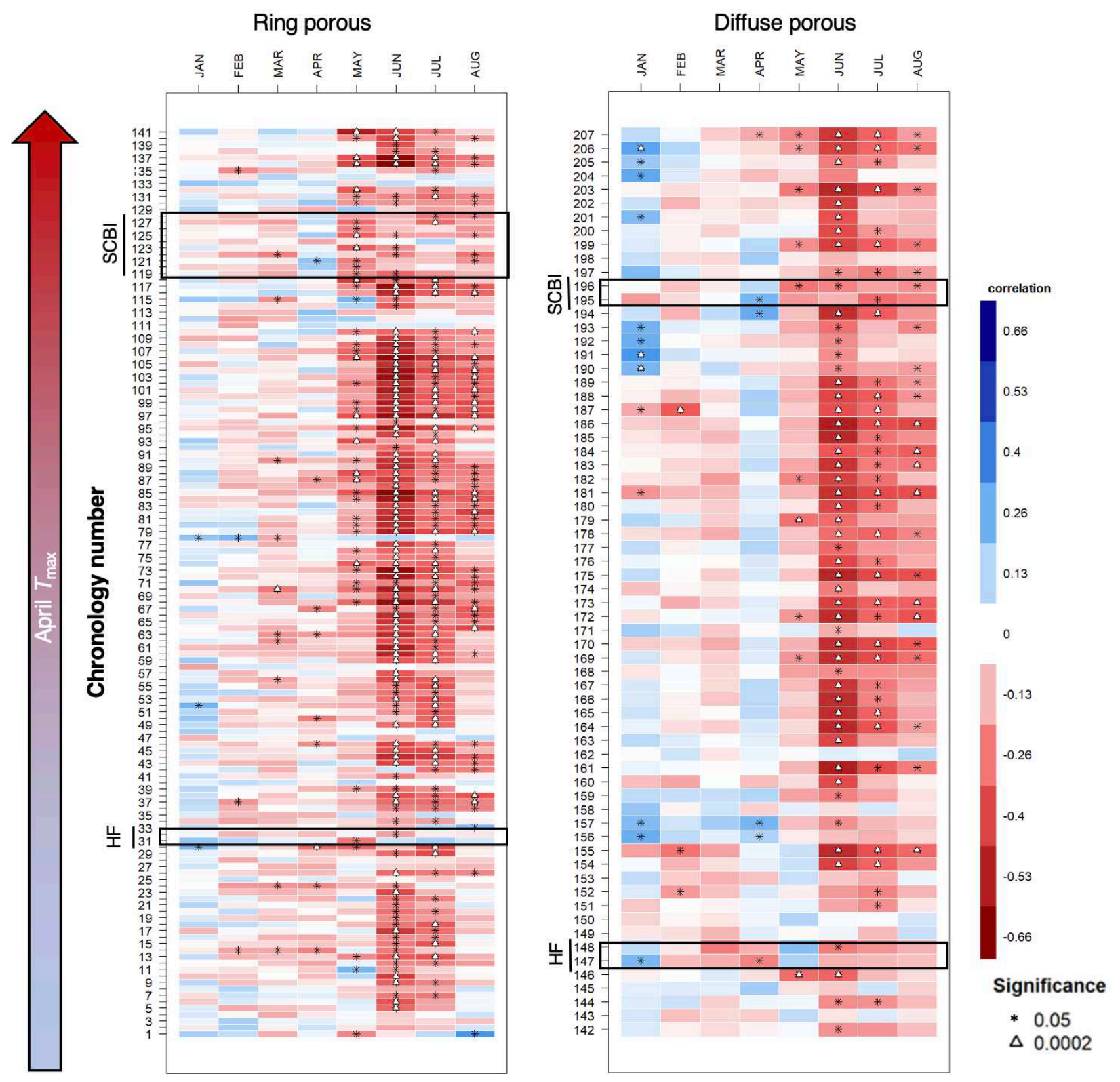

Figure 3 | Sensitivity of annual growth, as derived from tree-rings, to monthly mean maximum temperatures $\left(\mathrm{T}_{\max }\right)$, for 207 chronologies from 108 sites across eastern North America (Extended Data Figure 1). Colors indicate the correlation between monthly $\mathrm{T}_{\max }$ and a dimensionless ring width index (RWI) derived from the multiple trees that form each chronology and emphasizing interannual variability associated with climate. Chronologies are grouped by xylem porosity and ordered by mean $\mathrm{April}_{\mathrm{max}}$. Plots are annotated to highlight records from our two focal sites, the Smithsonian Conservation Biology Institute (SCBI) and Harvard Forest (HF) (Extended Data Table 1). Species analyzed and numbers of significant correlations to $\mathrm{T}_{\max }$ are summarized in Extended Data Table 3, and chronology details are given in SI Table 1. 


\section{Discussion}

189 Together, our results demonstrate that warmer spring temperatures in the temperate deciduous

190 forests of eastern North America advance the phenology of tree stem growth but have little

191 effect on annual woody productivity (Figs. 1- 3). The observed phenological advance in the start

192 of stem growth under warmer springs parallels phenological advances observed for canopy

193 foliage (Fig. 2a-b) 2,4,5 and $N E E^{2,4}$. However, inconsistent with the concept that an earlier start to

194 growth would increase annual woody productivity, we demonstrate that warmer springs

195 hasten the cessation of stem expansion and thereby have negligible effect on total annual

196 growth for most species and locations (Fig. 3). Our observations suggest that the cessation of

197 rapid stem expansion, which occurs mid-summer near the time of peak canopy greenness

198 (Extended Data Figure 2) ${ }^{4}$, is likely driven by cues other than photosynthate limitation, such as

199 daylength or sink limitation, which also play an important role in autumn leaf senescence ${ }^{17,23,31}$.

200 Our tree-ring analysis (Fig. 3) demonstrates that the primary effect of warming temperatures on

201 annual tree growth is not an augmentation through an earlier start to growth, but rather a

202 reduction associated to drought stress during the peak growing season ${ }^{26}$. Warm springs may

203 also amplify summer drought stress in some times and places, effectively canceling out any

204 positive effects of an extended growing period ${ }^{3,32}$; however, spring temperatures and summer

205 Standardized Precipitation Evapotranspiration Index ${ }^{33}$ were uncorrelated within our

206 dendrometer band analysis, implying that the effects of warm spring temperatures on growth

207 phenology elucidated here (Fig. 1) were not attributable to summer drought. 
208 Our finding that interannual variation in woody growth is more strongly linked to conditions

209 during the peak growing season than to growing season length aligns with parallel findings for

$210 N E E^{13,14}$. However, there is also a disconnect with findings that NEE is at least modestly greater

211 in years with warm springs ${ }^{2}$ or long growing seasons ${ }^{4,13,14}$. Warming advances spring phenology

212 and may advance or delay autumn senescence depending on timing of warming and water

213 availability ${ }^{12,34,35}$, with delays more common across eastern North America, ${ }^{2-4}$ implying that

214 warming temperatures are lengthening the period from peak stem growth to the cessation of

$215 \mathrm{CO}_{2}$ uptake by the ecosystem. We show that the extra $\mathrm{C}$ fixation in years with warm springs

216 does not substantially augment woody growth, but it remains unclear how it is allocated within

217 the ecosystem. There are two main possibilities, which hold contrasting implications for the

218 response of forest $\mathrm{C}$ balance to rising spring temperatures.

219 One possibility is that extra photosynthate in years with warm springs may be allocated to

220 woody growth without affecting diameter growth in the current year. It is theoretically possible

221 that extra $\mathrm{C}$ is allocated to cell wall thickening, a process that lags behind stem expansion ${ }^{36}$, or

222 to a thicker layer of higher-density latewood, resulting in formation of more C-dense wood in

223 years with warm springs. However, existing evidence indicates that warm springs have a

224 neutral or negative effect on latewood width ${ }^{37-39}$, which is more strongly controlled by summer

225 drought stress ${ }^{37,38}$, suggesting that a positive effect of warm springs on the total C content of

226 annual rings is unlikely. Extra C could also be saved within trees as non-structural

227 carbohydrates and used towards growth the following year ${ }^{40,41}$, potentially including an earlier

228 start to growth ${ }^{31}$. Extension of our tree-ring analysis revealed weak correlation between April

$229 T_{\max }$ and growth the following year (sig. pos. correlations for 5/142 RP and 3/66 DP species-site 
combinations, Fig. Extended Data Figure 7), although predominantly positive (non-significant)

231 correlations in RP species suggests that this dynamic may weakly influence their annual

232 growth. Thus, warm springs are unlikely to provide substantial, sustained C sinks under

233 warming spring temperatures.

234 A second possibility is that any additional C fixed during years with warm springs may be

235 allocated to plant functions other than stem growth, including respiration, reproduction, and

236 production of foliage, roots ${ }^{24}$, or root exudates. Much of this $\mathrm{C}$ would have a relatively short

237 residence time within the ecosystem, and C loss through fall or winter respiration may offset

238 gains from an earlier spring ${ }^{3,42}$. However, $\mathrm{C}$ allocated to nonstructural carbohydrates or

239 relatively short-lived plant tissues would typically remain in the ecosystem beyond the end of

240 the year ${ }^{40}$, such that the long-term effect of warm springs on the forest $C$ balance would not be

241 captured in analyses of interannual variation ${ }^{2,13,14}$. Studies within or including the temperate

242 deciduous biome that examined long-term trends in growing season length and ecosystem C

243 uptake $2,4,10,11$ - as opposed to their interannual variation - showed increasing trends in both

244 variables, suggesting that the $\mathrm{C}$ not allocated to woody productivity within the current year has

245 a multi-year residence time within the ecosystem. However, given our finding that warm

246 springs do not significantly enhance woody productivity, this C is likely to have a relatively

247 short residence time within the ecosystem.

248 Thus, a distinction between interannual variation and directional change may be critical when

249 considering how directional climate change is likely to affect tree growth and ecosystem C

250 dynamics. As discussed above, temporal lags between $\mathrm{C}$ uptake and release imply that the full 
251 effects of warm spring temperatures on forest woody productivity and C cycling are unlikely to

252 be apparent in analyses of interannual variation (including this analysis) ${ }^{43}$. Moreover,

253 acclimation of trees to warming temperatures ${ }^{44}$ and, on longer time scales, species adaptations

254 and shifts in community composition ${ }^{45}$ are likely to alter the phenology of forest $\mathrm{C}$ cycling. If we

255 look across spatial gradients where the latter have had time to play out, we see that warmer

256 spring temperatures are associated with earlier leaf-out ${ }^{6}$ and longer growing seasons, which in

257 turn are are correlated with greater tree growth ${ }^{46}$, woody productivity ${ }^{47}$, and $N E E^{48}$. Thus,

258 warming spring temperatures are expected to increase the biophysical potential for annual tree

259 growth, but that potential is not being realized on an interannual time frame.

260 As climate change accelerates and spring temperatures become increasingly warmer, growing

261 seasons will start earlier; however, barring rapid acclimation of forests to the warming

262 conditions, an earlier onset of growth in the spring is unlikely to provide the sustained increase

263 in $\mathrm{CO}_{2}$ sequestration and ensuant negative climate change feedback that is anticipated in most

264 climate forecasting models ${ }^{2,3,17,18}$. Rather, the dominant effect of rising temperatures on forest

265 woody productivity will be a negative effect of high summer temperatures, which constitutes a

266 positive feedback to climate change.

267 Methods

268 Dendrometer band analysis

269 Dendrometer band measurements were collected at $\mathrm{SCBI}^{49}$ and Harvard Forest ${ }^{4,25}$, both part of 270 the Forest Global Earth Observatory (ForestGEO) ${ }^{50,51}$. SCBI $\left(38.8935^{\circ} \mathrm{N}, 78.1454^{\circ}\right.$ W; elevation 
273-338 m.a.s.1.) is located in the Blue Ridge Mountains at the northern end of Shenandoah

272 National Park, $5 \mathrm{~km}$ south of Front Royal, Virginia. The forest is secondary and mixed age,

273 having established in the mid-19th century after conversion from agricultural fields ${ }^{49}$. Dominant

274 canopy species within the 25.6 ha ForestGEO plot include tulip poplar (Liriodendron tulipifera L.),

275 oaks (Quercus spp.), and hickories (Carya spp.). ${ }^{27}$. The climate is humid temperate, with 1950-2019

276 mean annual precipitation of $1018 \mathrm{~mm}$ and temperatures averaging $1^{\circ} \mathrm{C}$ in January and $24^{\circ} \mathrm{C}$ in

$277 \mathrm{July}^{46}$.

Harvard Forest $\left(42.5388^{\circ} \mathrm{N}, 72.1755^{\circ} \mathrm{W}, 340-368\right.$ m.a.s.l.) is located near the central

Massachusetts town of Petersham. The forest is secondary and mixed age, having re-established around the beginning of the 20th century following agricultural use and significant hurricane damage in 1938. Dominant species within the 35 ha ForestGEO plot are hemlock (Tsuga canadensis (L.) Carrière), oak (Quercus spp.) and red maple (Acer rubrum L.). The climate is temperate continental, with 1950-2019 mean annual precipitation of $1104 \mathrm{~mm}$ and temperatures 284 averaging $-5^{\circ} \mathrm{C}$ in January and $22^{\circ} \mathrm{C}$ in July ${ }^{46}$.

285 Metal dendrometer bands were installed on 941 trees within the SCBI and Harvard Forest 286 ForestGEO plots. Bands were placed on dominant species, including two diffuse- and two ring287 porous species at SCBI and eight diffuse- and three ring-porous species at Harvard Forest 288 (Extended Data Table 1). Bands were measured with a digital caliper approximately every 1-2 weeks within the growing season from 2011-2020 at SCBI and 1998-2003 at Harvard Forest. The 290 number of bands measured at each site fluctuated slightly as trees were added or dropped from 291 the census (e.g., because of tree mortality). Across years, the number of bands sampled 
292 averaged 129 (range: 91-138) at SCBI and 717 (range: 700-755) at Harvard Forest. In total, our

293 analysis included 2459 tree-years (Extended Data Table 1).

294 Measurements were timed to begin before the beginning of spring growth and to continue 295 through the cessation of growth in the fall. At SCBI, the median start date was April 14, which 296 was adjusted forward when early leaf-out of understory vegetation was observed, with the 297 earliest start date being March 30 (in 2020). Measurements were continued through to fall leaf 298 senescence, with the median end date being October 17 and the latest end date November 26 299 (2012). Timing of measurements at Harvard Forest were similar, with the median start date of 300 April 23 and median end date of October 30. 1998 was an anomalous year where initial 301 measurements were taken on January 5, but not taken again until April 15. The latest end date 302 was November 11, 2002.

303 The raw dendrometer band data were manually inspected before analysis. We screened the 304 data for three classes of errors. First, when a measurement was drastically different from 305 previous and following measurements, it was assumed to be a human error and the datapoint 306 was removed. Second, when measurements remained essentially unchanged for several 307 readings, followed by a sudden jump then return to a normal growth pattern, this was assumed 308 to be a case where the band was stuck on the tree bark and then released. In these cases, the full 309 annual record for the tree was removed. Third, data points that deviated substantially from 310 normal growth patterns, but for unknown causes, were removed. If a majority of the data points 311 fell into this class within a tree-year, the entire year was removed from the analysis. 
312 We fit a five-parameter logistic growth model ${ }^{28}$ to dendrometer band data from each tree-year

313 to define phenological dates and growth rates (Fig. 1). In particular, we model the observed

314 diameter at breast height $(\mathrm{DBH})$ on a given day of the year (DOY; i.e., julian days) as:

$$
D B H=L+\frac{K-L}{\left.1+1 / \theta \cdot \exp \left[-r\left(D O Y-D O Y_{i p}\right) / \theta\right)\right]^{\theta}}
$$

316 Here, $L$ and $K$ are lower and upper asymptotes of the model, corresponding to DBH at the

317 beginning and end of the year, respectively. $D O Y_{i p}$ is the day of year where the inflection point

318 in growth rate occurs, $r$ shapes the slope of the curve at the inflection point, and $\theta$ is a tuning

319 parameter controlling the slope of the curve toward the upper asymptote. The DOY on which

320 maximum growth occurs, $D O Y_{g_{\max }}$ (Fig. 1), occurs on $D O Y_{i p}$ when $\theta=1$. The model was fit in $\mathrm{R}$

$321 \mathrm{v} 4.0$ using the functions developed in the Rdendrom package ${ }^{28}$. These functions take the time-

322 series of manual dendrometer band measurements and return maximum-likelihood optimized

323 values of the above five parameters that best predict $\mathrm{DBH}$ for each day of year. We then

324 modeled DBH using these optimal parameter values in our logistic growth model and extracted

325 the intra-annual growth variables of interest (Fig. 1).

326 After fitting the growth model, we removed tree-years with poor fits. Models were judged to be

327 poorly fit if certain modeled growth characteristics fell outside of the logical range. Modeled fits

328 for tree-years were removed under five conditions: (1) single day growth rates were $\geq 2$

329 standard deviations away from the mean for each wood-type (SCBI = 2, Harvard Forest = 34);

330 (2) $D O Y_{i p}$ was $\geq 2$ standard deviations away from the mean for its xylem architecture group,

331 year, and site $(\mathrm{SCBI}=53$, Harvard Forest $=106)$; $(3)$ tree-years with small or negligible total 
332 growth $(\triangle D B H \leq 0.02 \mathrm{~mm} ; \mathrm{SCBI}=0$, Harvard Forest $=66)$; (4) model fit predicted total yearly 333 growth to take longer than 365 days, indicating poor model fit $(\mathrm{SCBI}=150$, Harvard Forest $=$

334 199); (5) models with unexplained sharp spikes in growth rate (SCBI = 0, Harvard Forest = 3);

335 and (6) poorly fit models that did not meet any of the above criteria $(\mathrm{SCBI}=2$, Harvard Forest =

336 0). At Harvard Forest the tag years removed through this method were proportional to the

337 original sample size, indicating that no species or size class was disproportionately removed

338 compared to others. At SCBI, a higher proportion of ring-porous trees were removed, the

339 majority falling under condition 4.

340 Canopy foliage phenology data for the years 2001-2018 were extracted for SCBI and Harvard

341 Forest from the MCD12Q2 V6 Land Cover Dynamics product (a.k.a. MODIS Global Vegetation

342 Phenology product $)^{52}$ via Google Earth Engine. Extracted pixels were those containing the

343 NEON tower at each site. Using daily MODIS 2-band Enhanced Vegetation Index data (EVI2) at

344 a spatial resolution of $500 \mathrm{~m}$, the product yields the timing of phenometrics (vegetation

345 phenology) over each year, including timing of greenup, midgreenup, and senescence as used

346 in this study.

347 For the dendrometer band and leaf phenology analyses, climate data corresponding to the

348 measurement periods were obtained from local weather stations at each focal site. For SCBI,

349 weather data were obtained from a meteorological tower adjacent to the ForestGEO plot, via the

350 ForestGEO Climate Data Portal v1.0 (https://forestgeo.github.io/Climate/) ${ }^{53}$. The R package

351 climpact (see www.climpact-sci.org) ${ }^{54}$ was used to plot temperatures for visual inspection and to

352 identify readings that were $>3$ standard deviations away from yearly means, which were 
353 labeled as outliers and removed from the dataset. Gaps in the SCBI meteorological tower data

354 were subsequently filled using temperature readings obtained from a National Center for

355 Environmental Information (NCEI) weather station located in Front Royal, Virginia

356 (https://www.ncdc.noaa.gov/cdo-web/datasets/GHCND/stations/GHCND:USC00443229/detail).

357 Daily temperature records for Harvard Forest, which had already been gap-filled based on

358 other local records, were obtained from the Harvard Forest weather station 55,56 . For each site, we

359 used records of daily maximum $\left(T_{\max }\right)$ and minimum temperatures $\left(T_{\min }\right)$.

360 The critical temperature window (CTW, Fig. 1), defined as the period over which $T_{\max }$ was

361 most strongly correlated with $\mathrm{DOY}_{25}$, was determined using the R package climwin ${ }^{57}$. This

362 package tests the correlation between one or more predictor climate variable and a biological

363 outcome variable over all consecutive time windows within a specified time-frame. It does so

364 by reporting the correlation and $\triangle A I C c$, the difference in Akaike Information Criterion corrected

365 for small sample size relative to a null model for each window. Here, we tested for correlation

366 between temperature predictor variables $\left(T_{\max }, T_{\min }\right)$ and biological outcome variable $D O Y_{25}$

367 over the time-frame from January 1 to the mean $D O Y_{25}$ for the species group (by xylem porosity)

368 and site (Extended Data Table 2). The time period yielding the lowest $\triangle A I C C$ was selected as the

369 CTW. Because $T_{\max }$ proved to have a generally stronger influence over $D O Y_{25}$ and other growth

370 parameters, we focused on this variable in our ultimate model, as opposed to $T_{\min }$. We defined

371 CTW for $D O Y_{25}$, as opposed to other growth phenology parameters, because spring

372 temperatures should have the most direct influence on this variable. 
373 To ensure that patterns were robust under an alternative definition of CTW, and to parallel the

374 monthly time windows used in our tree-ring analysis (detailed below; Fig. 3, Extended Data

375 Figure 6-7), we also ran analyses where we fixed the CTW to be the month of April. This was

376 consistent with the periods identified by climwin for ring- and diffuse-porous species groups at

377 both sites, all of which included all or part of April (Extended Data Table 2).

378 Correlation between the dendrometer band-derived growth parameters $\left(D O Y_{25}, D O Y_{50}, D O Y_{75}\right.$,

$379 D O Y_{g_{\max }}, L_{P G S}, g_{\max }$, and $\left.\triangle D B H\right\}$, Fig. 1) and spring temperatures were assessed using a linear

380 mixed model in a hierarchical Bayesian framework. Analyses were run for both $T_{\max }$ and $T_{\min }$,

381 with qualitatively similar results, but we present only results for $T_{\max }$, which had overall

382 stronger correlation with growth parameters. Mixed effects models were used to test the

383 response of growth phenology variables to fixed effects of xylem porosity and mean $T_{\max }$ (or

$\left.384 T_{\min }\right)$ during the CTW, along with random effects of species and of individual tree. We ran

385 separate models for each species group at each site, and for the response of all growth

386 phenology variables to $T_{\max }\left(\right.$ or $T_{\min }$ ). This mixed-effect model was run within a hierarchical

387 Bayesian framework and fit using the rstanarm R interface to the Stan programming

388 language ${ }^{58,59}$. In all cases unless otherwise specified, all prior distributions are set to be the

389 weakly informative defaults.

390 To rule out the possibility that observed patterns were strongly influenced by summer drought,

391 we examined the relationship between spring tempreatures and summer Standardized

392 Precipitation Evapotranspiration Index ${ }^{33}$. The latter was obtained from the ForestGEO Climate

393 Data Portal v1.0 (https://forestgeo.github.io/Climate/)53,60,61. Linear models were run with 4-, 6-, 
394 and 12-month SPEI values of June, July, and August vs April $T_{\max }$ to determine if warm spring

395 temperatures lead to greater summer drought stress. No significant correlations were found (all

$396 \mathrm{p}>0.05)$.

397 Tree-ring analysis

398 We analyzed tree-ring records for 108 sites, including our focal sites. All cores had been

399 previously collected, cross-dated, and measured using standard collection and processing

400 methodologies ${ }^{62}$.

401 Dominant tree species were cored at both $\mathrm{SCBI}^{27,49}$ and Harvard Forest ${ }^{4,63,64}$ following sampling

402 designs that covered a broad range of DBH. We analyzed records for the ring- and diffuse-

403 porous species at each site (Extended Data Table 1), but excluded species with other xylem

404 architectures (Juglans nigra L. at SCBI, Tsuga canadensis at Harvard Forest). We studied a total of

405976 cores which included 12 species at SCBI and 4 species at Harvard Forest (Extended Data

406 Table 1).

407 The tree-ring records from our focal sites were complemented with a much larger collection

408 spanning 106 deciduous and mixed forest sites in Eastern North America ${ }^{26,65}$. Again, records

409 were limited to broadleaf deciduous species with clearly defined xylem porosity (i.e., excluding

410 semi-ring porous).

411 For each species-site combination, we converted tree-ring records into the dimensionless RWI to

412 emphasize interannual variability associated with climate. ${ }^{66} \mathrm{~A} 2 / 3 \mathrm{rds} n$ spline was applied to

413 each core using ARSTAN to produce standardized ring-width series; $n$ is the number of years in 
414 each series ${ }^{66,67}$. An adaptive power transformation, a process that also stabilises the variance 415 over time ${ }^{68}$, was used to minimize the influence of outliers in all series. Low series replication, 416 often in the earliest portions of a chronology collection, can also inflate the variance of tree-ring 417 records ${ }^{69}$. The $1 / 3$ rds spline method was chosen when replication in the inner portion of each 418 chronology (ca. inner 30-50 yr of each record depending on full chronology length) was less 419 than three trees. When replication was greater than $n=3$ trees, we used the average correlation 420 between raw ring-width series (rbar) method. The robust biweight mean chronology (RWI) for 421 each species-site combination was calculated from the ring-width indices following variance 422 stabilisation ${ }^{67}$. We defined chronology start year (Extended Data Table 1) as the year where 423 subsample signal strength (SSS) passed a threshold of SSS $=0.8$, or where $\geq 80 \%$ of the 424 population signal was captured in the chronology.

425 For the analysis of correlation between RWI and climate variables, we obtained monthly $T_{\max }$ 426 and $T_{\min }$ data for 1901-2019 from CRU v.4.04. ${ }^{70}$ Correlations between monthly climate and $R W I$ 427 were assessed using 'dplR'71 and 'bootRes'72 in R v 4.0 (R Core Team, 2020), which correlated 428 functions and bootstrapped confidence intervals for these relationships ${ }^{73}$. We analyzed these 429 correlations for January through September of the current year (presented in Fig. 3, Extended 430 Data Figure 6). To test for potential lag effects of spring temperatures on growth the following 431 year, we also ran a version of the analysis extending back to include climate of every month of 432 the previous year (Extended Data Figure 7). Correlations and significance levels for months 433 April-August are given in SI Table 1. 
434 We used a multivariate model to test for joint effects of April and summer $T_{\max }$ on RWI. We

435 began by testing univariate correlations of $T_{\max }$ over three summer windows: June, June-July,

436 and May-August. Having determined that, among these, June-July explained the most

437 variation, we then analyzed the joint effects of April $T_{\max }$ and June-July $T_{\max }$ on RWI for each

438 chronology independently using the base $\operatorname{lm}()$ function in R. Slopes and p-values for each

439 chronology are given in SI Table 1.

\section{Acknowledgements}

441 We gratefully acknowledge all researchers who assisted with data collection in the field and 442 laboratory, particularly Tsun Fung Au, Joshua Bregy, James Dickens, Karen Heeter, Anna 443 Hennage, Daniel King, James McGee, Benjamin Lockwood, Jennifer McGarvey, Victoria 444 Meakem, Josh Oliver, Jessica Shue, Karly Schmidt-Simard, Brandon Strange, Alyssa Terrell, 445 Brynn Taylor, Michael Thornton, Senna Robeson, Matt Wenzel, and Luke Wylie. Thanks to 446 David A. Orwig and members of the ForestGEO Ecosystesms \& Climate Lab at SCBI for helpful 447 feedback. The research was funded by ForestGEO (Smithsonian). Collection of tree-ring 448 samples was funded by a USDA Agriculture and Food Research Initiative grant 2017-6701344926191 and from the Indiana University Vice Provost for Research Faculty Research Program.

\section{Author Contributions}

451 Cameron Dow and Kristina J. Anderson-Teixeira conceived the ideas and designed the study;

452 Cameron Dow, Loïc D’Orangeville, Erika B. Gonzalez-Akre, Ryan Helcoski, Grant L. Harley, 
453 Justin T. Maxwell, Ian R. McGregor, William McShea, Neil Pederson, Alan J. Tepley, and

454 Kristina J. Anderson-Teixeira collected or oversaw collection of data; Cameron Dow, Albert Y.

455 Kim, Valentine Herrmann, Justin T. Maxwell, Ian R. McGregor, Sean McMahon analyzed the

456 data or provided analytical tools; Cameron Dow and Kristina J. Anderson-Teixeira led the

457 writing of the manuscript. All authors contributed critically to the drafts and gave final

458 approval for publication.

459 Additional Information

460 Supplementary Information is available for this paper.

461 Correspondence and requests for materials should be addressed to Kristina Anderson-Teixeira

462 (teixeirak@si.edu).

463

464

465

466

467

468

469

470

471

472

473

474

475

\section{References}

1. Jeong, S.-J., Ho, C.-H., Gim, H.-J. \& Brown, M. E. Phenology shifts at start vs. End of growing season in temperate vegetation over the Northern Hemisphere for the period 1982. Global Change Biology 17, 2385-2399 (2011).

2. Keenan, T. F. et al. Net carbon uptake has increased through warming-induced changes in temperate forest phenology. Nature Climate Change 4, 598-604 (2014).

3. Buermann, W. et al. Widespread seasonal compensation effects of spring warming on northern plant productivity. Nature 562, 110-114 (2018).

4. Finzi, A. C. et al. Carbon budget of the Harvard Forest Long-Term Ecological Research site: Pattern, process, and response to global change. Ecological Monographs 90, e01423 (2020).

5. Stuble, K. L., Bennion, L. D. \& Kuebbing, S. E. Plant phenological responses to experimental warmingA synthesis. Global Change Biology 27, 4110-4124 (2021). 
6. Delgado, M. del M. et al. Differences in spatial versus temporal reaction norms for spring and autumn phenological events. Proceedings of the National Academy of Sciences 202002713 (2020) doi:10.1073/pnas.2002713117.

7. Menzel, A. \& Fabian, P. Growing season extended in Europe. Nature 397, 659-659 (1999).

8. Menzel, A. et al. European phenological response to climate change matches the warming pattern. Global Change Biology 12, 1969-1976 (2006).

9. Ibáñez, I. et al. Forecasting phenology under global warming. Philosophical Transactions of the Royal Society B: Biological Sciences 365, 3247-3260 (2010).

10. Keeling, C. D., Chin, J. F. S. \& Whorf, T. P. Increased activity of northern vegetation inferred from atmospheric CO 2 measurements. Nature 382, 146-149 (1996).

11. Dragoni, D. et al. Evidence of increased net ecosystem productivity associated with a longer vegetated season in a deciduous forest in south-central Indiana, USA. Global Change Biology 17, 886-897 (2011).

12. Crabbe, R. A. et al. Extreme warm temperatures alter forest phenology and productivity in Europe. Science of The Total Environment 563-564, 486-495 (2016).

13. Zhou, S. et al. Explaining inter-annual variability of gross primary productivity from plant phenology and physiology. Agricultural and Forest Meteorology 226-227, 246-256 (2016).

14. Fu, Z. et al. Maximum carbon uptake rate dominates the interannual variability of global net ecosystem exchange. Global Change Biology 25, 3381-3394 (2019).

15. Xue, B.-L. et al. Global patterns of woody residence time and its influence on model simulation of aboveground biomass. Global Biogeochemical Cycles 31, 821-835 (2017).

16. Russell, M. B. et al. Residence Times and Decay Rates of Downed Woody Debris Biomass/Carbon in Eastern US Forests. Ecosystems 17, 765-777 (2014).

17. Zani, D., Crowther, T. W., Mo, L., Renner, S. S. \& Zohner, C. M. Increased growingseason productivity drives earlier autumn leaf senescence in temperate trees. 7 (2020).

18. Ahlström, A., Schurgers, G., Arneth, A. \& Smith, B. Robustness and uncertainty in terrestrial ecosystem carbon response to CMIP5 climate change projections. Environmental Research Letters 7, 044008 (2012).

19. Pan, Y. et al. A Large and Persistent Carbon Sink in the World's Forests. Science 333, 988993 (2011).

20. Friedlingstein, P. et al. Global Carbon Budget 2020. Earth System Science Data 12, 32693340 (2020). 
21. Pugh, T. A. M. et al. Role of forest regrowth in global carbon sink dynamics. Proceedings of the National Academy of Sciences 116, 4382-4387 (2019).

22. Arora, V. K. et al. Carbonconcentration and carbonclimate feedbacks in CMIP6 models and their comparison to CMIP5 models. Biogeosciences 17, 4173-4222 (2020).

23. Keenan, T. F. \& Richardson, A. D. The timing of autumn senescence is affected by the timing of spring phenology: Implications for predictive models. Global Change Biology 21, 2634-2641 (2015).

24. Zohner, C. M., Renner, S. S., Sebald, V. \& Crowther, T. W. How changes in spring and autumn phenology translate into growth-experimental evidence of asymmetric effects. Journal of Ecology 109, 2717-2728 (2021).

25. D'Orangeville, L. et al. Peak radial growth of diffuse-porous species occurs during periods of lower water availability than for ring-porous and coniferous trees. Tree Physiology (2021) doi:10.1093/treephys/tpab101.

26. D'Orangeville, L. et al. Drought timing and local climate determine the sensitivity of eastern temperate forests to drought. Global Change Biology 24, 2339-2351 (2018).

27. Helcoski, R. et al. Growing season moisture drives interannual variation in woody productivity of a temperate deciduous forest. New Phytologist 223, 1204-1216 (2019).

28. McMahon, S. M. \& Parker, G. G. A general model of intra-annual tree growth using dendrometer bands. Ecology and Evolution 5, 243-254 (2015).

29. Parmesan, C. \& Yohe, G. A globally coherent fingerprint of climate change impacts across natural systems. Nature 421, 37-42 (2003).

30. Friedl, M. A. et al. A tale of two springs: Using recent climate anomalies to characterize the sensitivity of temperate forest phenology to climate change. Environmental Research Letters 9, 054006 (2014).

31. Fu, Y.S. H. et al. Variation in leaf flushing date influences autumnal senescence and next year's flushing date in two temperate tree species. Proceedings of the National Academy of Sciences 111, 7355-7360 (2014).

32. Zhang, J. et al. Drought limits wood production of Juniperus przewalskii even as growing seasons lengthens in a cold and arid environment. CATENA 196, 104936 (2021).

33. Vicente-Serrano, S. M., Beguería, S. \& López-Moreno, J. I. A Multiscalar Drought Index Sensitive to Global Warming: The Standardized Precipitation Evapotranspiration Index. Journal of Climate 23, 1696-1718 (2010).

34. Zohner, C. M. \& Renner, S. S. Ongoing seasonally uneven climate warming leads to earlier autumn growth cessation in deciduous trees. Oecologia 189, 549-561 (2019). 
35. Xie, Y., Wang, X., Wilson, A. M. \& Silander, J. A. Predicting autumn phenology: How deciduous tree species respond to weather stressors. Agricultural and Forest Meteorology 250-251, 127-137 (2018).

36. Cuny, H. E. et al. Woody biomass production lags stem-girth increase by over one month in coniferous forests. Nature Plants 1, 15160 (2015).

37. Tardif, J. C. \& Conciatori, F. Influence of climate on tree rings and vessel features in red oak and white oak growing near their northern distribution limit, southwestern Quebec, Canada. Canadian Journal of Forest Research 36, 2317-2330 (2006).

38. Roibu, C.-C. et al. The Climatic Response of Tree Ring Width Components of Ash (Fraxinus excelsior L.) And Common Oak (Quercus robur L.) From Eastern Europe. Forests 11, 600 (2020).

39. Kern, Z. et al. Multiple tree-ring proxies (earlywood width, latewood width and $\delta 13 C$ ) from pedunculate oak (Quercus robur L.), Hungary. Quaternary International 293, 257-267 (2013).

40. Trumbore, S., Gaudinski, J. B., Hanson, P. J. \& Southon, J. R. Quantifying ecosystematmosphere carbon exchange with a 14C label. Eos, Transactions American Geophysical Union 83, 265-268 (2002).

41. Richardson, A. D. et al. Seasonal dynamics and age of stemwood nonstructural carbohydrates in temperate forest trees. New Phytologist 197, 850-861 (2013).

42. Oishi, A. C. et al. Warmer temperatures reduce net carbon uptake, but do not affect water use, in a mature southern Appalachian forest. Agricultural and Forest Meteorology 252, 269282 (2018).

43. Kannenberg, S. A. et al. Linking drought legacy effects across scales: From leaves to tree rings to ecosystems. Global Change Biology 25, 2978-2992 (2019).

44. Gessler, A., Bottero, A., Marshall, J. \& Arend, M. The way back: Recovery of trees from drought and its implication for acclimation. The New phytologist 228, 1704-1709 (2020).

45. Fisichelli, N. A., Frelich, L. E. \& Reich, P. B. Temperate tree expansion into adjacent boreal forest patches facilitated by warmer temperatures. Ecography 37, 152-161 (2014).

46. Anderson-Teixeira, K. J. et al. Joint effects of climate, tree size, and year on annual tree growth derived from tree-ring records of ten globally distributed forests. Global Change Biology n/a, (2021).

47. Banbury Morgan, R. et al. Global patterns of forest autotrophic carbon fluxes. Global Change Biology gcb.15574 (2021) doi:10.1111/gcb.15574. 
48. Churkina, G., Schimel, D., Braswell, B. H. \& Xiao, X. Spatial analysis of growing season length control over net ecosystem exchange. Global Change Biology 11, 1777-1787 (2005).

49. Bourg, N. A., McShea, W. J., Thompson, J. R., McGarvey, J. C. \& Shen, X. Initial census, woody seedling, seed rain, and stand structure data for the SCBI SIGEO Large Forest Dynamics Plot: Ecological Archives E094-195. Ecology 94, 2111-2112 (2013).

50. Anderson-Teixeira, K. J. et al. CTFS-ForestGEO : A worldwide network monitoring forests in an era of global change. Global Change Biology 21, 528-549 (2015).

51. Davies, S. J. et al. ForestGEO: Understanding forest diversity and dynamics through a global observatory network. Biological Conservation 253, 108907 (2021).

52. Friedl, M., Gray, J. \& Sulla-Menashe, D. MCD12Q2 MODIS/Terra+Aqua Land Cover Dynamics Yearly L3 Global 500m SIN Grid V006. (2019) doi:10.5067/MODIS/MCD12Q2.006.

53. Anderson-Teixeira, K. et al. Forestgeo/Climate: Initial release. (2020) doi:10.5281/ZENODO.4041609.

54. Benestad, R. E., Hanssen-Bauer, I. \& Chen, D. Empirical-statistical downscaling. (World Scientific Pub Co Inc, 2008).

55. Boose, E. \& Gould, E. Shaler Meteorological Station at Harvard Forest 1964-2002. (2021) doi:10.6073/PASTA/213335F5DAA17222A738C105B9FA60C4.

56. Boose, E. Fisher Meteorological Station at Harvard Forest since 2001. (2021) doi:10.6073/PASTA/69E92642B512897032446CFE795CFFB8.

57. van de Pol, M. et al. Identifying the best climatic predictors in ecology and evolution. Methods in Ecology and Evolution 7, 1246-1257 (2016).

58. Gabry, J. et al. Rstanarm: Bayesian Applied Regression Modeling via Stan. (2020).

59. Stan_Development_Team. Stan Modeling Language Users Guide and Reference Manual, 2.28. (2019).

60. Beguería, S., Vicente-Serrano, S. M., Reig, F. \& Latorre, B. Standardized precipitation evapotranspiration index (SPEI) revisited: Parameter fitting, evapotranspiration models, tools, datasets and drought monitoring. International Journal of Climatology 34, 3001-3023 (2014).

61. Vicente-Serrano, S. M., Beguería, S. \& López-Moreno, J. I. A Multiscalar Drought Index Sensitive to Global Warming: The Standardized Precipitation Evapotranspiration Index. Journal of Climate 23, 1696-1718 (2010).

62. Stokes, M. A. \& Smiley, T. L. An Introduction to Tree-ring Dating. (University of Arizona Press, 1968). 
63. Alexander, M. R. et al. The potential to strengthen temperature reconstructions in ecoregions with limited tree line using a multispecies approach. Quaternary Research 92, 583-597 (2019).

64. Dye, A. et al. Comparing tree-ring and permanent plot estimates of aboveground net primary production in three eastern U.S. forests. Ecosphere 7, e01454 (2016).

65. Maxwell, J. T. et al. Sampling density and date along with species selection influence spatial representation of tree-ring reconstructions. Climate of the Past 16, 1901-1916 (2020).

66. Methods of Dendrochronology: Applications in the Environmental Sciences. (Springer Netherlands, 1990). doi:10.1007/978-94-015-7879-0.

67. Cook, E. R. A Time Series Analysis Approach to Tree Ring Standardization. vol. PhD (University of Arizona, 1985).

68. Cook, E. R. \& Peters, K. Calculating unbiased tree-ring indices for the study of climatic and environmental change. The Holocene 7, 361-370 (1997).

69. Jones, P. D., Osborn, T. J. \& Briffa, K. R. Estimating sampling errors in large-scale temperature averages. Journal of Climate 10, 2548-2568 (1997).

70. Harris, I., Osborn, T. J., Jones, P. \& Lister, D. Version 4 of the CRU TS monthly highresolution gridded multivariate climate dataset. Scientific Data 7, (2020).

71. Bunn, A. G. A dendrochronology program library in R (dplR). Dendrochronologia 26, 115124 (2008).

72. Zang, C. \& Biondi, F. Dendroclimatic calibration in R: The bootRes package for response and correlation function analysis. Dendrochronologia 31, 68-74 (2013).

73. Biondi, F. \& Waikul, K. DENDROCLIM2002 : A C++ program for statistical calibration of climate signals in tree-ring chronologies. Computers $\mathcal{E}$ Geosciences 30, 303-311 (2004). 


\section{Supplementary Files}

This is a list of supplementary files associated with this preprint. Click to download.

- DowSITable1.xIsx

- DowExtendedData.pdf 